\title{
La democracia boliviana: Entre la consolidación, la profundización y la incertidumbre. Un análisis contextualizado de los resultados de las elecciones de 2002 en Bolivia ${ }^{1}$
}

\section{RESUMEN}

En este ensayo analizamos las elecciones bolivianas de 2002. No nos centramos únicamente en los resultados, que fueron sorprendentes, sino también tratamos de conectar estos resultados con desarrollos actuales del sistema de partidos políticos, con la brecha entre sociedad y mundo político, y con las políticas neoliberales implementadas en Bolivia a partir de 1985. Sugerimos que sólo un análisis de gestión política no basta, y que necesitamos incluir un análisis detallado del proceso político y de las políticas económicas para poder comprender la crisis actual. Eventos recientes que culminaron en la dimisión del presidente Sánchez de Lozada en octubre 2003 confirman la sospecha que el sistema partidario boliviano ha sido incapaz de remediar la "deficiencia representativa", lo que contribuyó al éxito de los partidos "antisistémicos" y a la convulsión social. En nuestro análisis, abordamos tanto lo económico y lo político, como también lo social, lo étnico y la dimensión de la cultura.

Palabras clave: democracia - consolidación democrática - deficiencia representativa - sistema de partidos políticos - Bolivia.

\section{ABSTRACT}

In this essay we analyse the Bolivian 2002 elections. We focus not only on the surprising results, but try to connect these to the recent developments within the Bolivian party system, the abyss between polity and society, and the neoliberal policies in place in Bolivia since 1985. We suggest that a mere analysis of institutional engineering and development will not do and that detailed exploration of political processes, and of politic-economic policies is in order to account for a party system in turmoil and for a

1 Este trabajo forma parte del Proyecto de Cooperación Internacional $\mathrm{N}^{\circ} 7020442$ relacionado con el Proyecto FONDECYT N ${ }^{\circ}$ 1020442: "Sociedad andina, municipio y etnicidad en el norte de Chile".

2 Centro de Estudios Rurales de El Colegio de Michoacán, CER, Martínez de Navarrete 505, Frac. Las Fuentes, 59690 Zamora, Michoacán. Email: assies@colmich.edu.mx

3 SCA/FSW, Vrije Universiteit Amsterdam, De Boelelaan 1081c, 1081 HV Amsterdam. Email: aj.salman@fsw.vu.nl society "at war" with its polity. Recent events in Bolivia, leading to the toppling of president Sánchez de Lozada on October $17^{\text {th }}$, seem to confirm that the incapacity of the existing party system to reform itself and to remedy the "representation deficit" of the Bolivian polity contributed to the rise of what are called the "anti-systemics", and to protests outbursts capable of disrupting the democratic institutionality. In our analysis, we focus both on economic and political, as well as on social, ethnic and political culture dimensions.

Key words: democracy - democratic consolidation representation deficit - party system - elections Bolivia.

Recibido: noviembre 2003. Manuscrito revisado aceptado: febrero 2004.

El día 17 de octubre de 2003, dimitió el presidente Sánchez de Lozada de Bolivia, luego de varias semanas de protestas sociales, represión policial y militar, y más de 70 víctimas. El presente ensayo fue escrito antes de esos eventos, tratando de analizar los resultados de las elecciones de 2002 y la crisis del sistema partidario en Bolivia, y logrando incluir en un "epílogo" los disturbios de febrero de 2003. No pudimos vaticinar el desenlace de octubre de ese año, aunque pronosticamos una difícil tarea para el presidente que asumió en agosto de 2002. No obstante la ausencia de un análisis específico de los acontecimientos más recientes, confiamos en que el presente ensayo contribuya a comprender por qué Bolivia pasó por la crisis de octubre de 2003 y por qué aún no puede llamarse una "democracia consolidada".

\section{Introducción}

Según los parámetros bolivianos, las elecciones de junio de 2002 se llevaron a cabo en una atmósfera de total orden y tranquilidad. Los resultados, aunque sorprendentes, fueron reconocidos sin mayores protestas por los contendientes. El proceso no sufrió interferencias de injerencia militar alguna, 
ninguna protesta callejera de envergadura o ningún político que amenace rechazar los resultados. ${ }^{4}$ Las protestas y acusaciones menores sobre pequeños fraudes en lugares de votación específicos no tuvieron suficiente peso como para dañar la imagen de una democracia ordenada y "normal". Puesto que ninguno de los candidatos obtuvo una mayoría absoluta, el nuevo presidente fue elegido por el Congreso -tal como indican las reglas electorales en Bolivia- entre los dos primeros en la votación, el candidato del MNR y anterior presidente, Gonzalo Sánchez de Lozada, y el candidato del MAS y líder de los cocaleros, Evo Morales. La elección de Sánchez de Lozada tuvo lugar el 4 de agosto y dos días después él asumió la presidencia por segunda vez.

Así, a primera vista, la democracia pareciera haberse establecido y consolidado en Bolivia. Sin embargo, si se mira más de cerca, la situación es mucho más compleja de lo que estas imágenes de normalidad sugieren. Hace ocho años, después de transcurridos 13 años de gobierno civil en Bolivia $^{5}$, Mainwaring y Scully (1995: 19) clasificaron al sistema de partidos boliviano como incipiente y débilmente institucionalizado, pero anotaron que éste estaba "mostrando algunas señales de estar logrando mayor solidez". El resultado de las elecciones indica claramente que ocurrió algo más que un desplazamiento "normal" de las preferencias electorales e hizo estragos con el sistema partidario. Uno de los tres partidos grandes, tradicionales y establecidos, ADN, no obtuvo ni el $4 \%$ de la votación. El MIR, otro de los grandes, cayó a un

4 Para ser exactos, sí hubo uno: Manfred Reyes Villa, de NFR. Sin embargo, según la mayoría de los comentarios, su filípica reflejaba mezquindad y no era una acusación seria de fraude. Reflejaba envidia, rabia y frustración por haber perjudicado él mismo su propia campaña debido a sus mentirosas declaraciones públicas y conexiones con la Secta Moon; esto último provocó que muchos católicos optaran por algún otro candidato.

5 Como tal, un verdadero logro en un país notoriamente inestable que ingresó al Libro Guinness de Records con 188 golpes de Estado en los 157 años entre 1825, el año de la Independencia, y 1982, año en que se dio el retorno a los gobiernos civiles (Van Lindert y Verkoren 1994: 17). A lo largo del siglo XIX, el promedio de duración de los períodos presidenciales era de dos años y medio, para el período 1900-1982 era de un año y 11 meses. De los 73 presidentes que tuvo el país desde 1825 hasta 1982, 33 gobernaron durante menos de un año (Lavaud 1991: 19). cuarto lugar aunque manteniendo su votación estable. De los dos partidos que habían surgido a principios de los ' 90 y parecían estar camino a su consolidación, UCS perdió fuertemente, mientras que CONDEPA fue virtualmente barrido del escenario. Su lugar fue parcialmente llenado por otro partido populista, NFR, dirigido por el anterior alcalde de Cochabamba, el Mayor Manfred Reyes Villa. Este partido salió en tercer lugar, apenas derrotado por un margen de algunos cientos de votos por el segundo (Cuadro 1).

Para sorpresa de muchos, el izquierdista MAS, de Evo Morales, se convirtió en el nuevo número dos. Los planteamientos de Morales son vistos con total desprecio por la mayor parte de los partidos establecidos. Y el partido que salió en quinto lugar, MIP, es dirigido por una persona que los otros consideran actúa en los márgenes de la legitimidad política, el líder campesino Felipe Quispe, el Mallku. ${ }^{6}$ De este modo, dos partidos que obtuvieron una votación impresionante son liderados por políticos que cosecharon el desprecio y fueron descalificados por los partidos que se consideran "establecidos" y "democráticos". En los últimos años, ellos se destacaron por las protestas fuera del Parlamento contra el gobierno de Banzer (1997-2002), contra las políticas neoliberales y contra la presunta corrupción e incompetencia de los políticos "tradicionalmente elitistas". Además, son partidos que expresan las voces del descontento indígena en Bolivia. El hecho de que estos partidos nuevos no sólo enfrenten la hostilidad "normal" de los oficialistas, sino se les niegue incluso su condición de ser los legítimos representantes de reivindicaciones de orden societal, sugiere que la democracia boliviana podría ser un régimen profundamente defectuoso.

En este ensayo enfocaremos dos cuestiones. En primer lugar, pareciera que el sistema de partidos boliviano, en vez de moverse en la dirección de una mayor solidez, estuviera pasando por un proceso de profunda agitación que refleja las tensiones que se han ido acumulando en la sociedad boliviana en el transcurso de las pasadas décadas. El país se encuentra aún lejos de las aguas tranquilas de la gobernabilidad democrática. En los términos propuestos por O'Donnell, el tránsito de los pasados 20 años hacia la consolidación e

\footnotetext{
6 Un título honorífico en los Andes.
} 


\begin{tabular}{|l|c|c|c|c|c|}
\hline PARTIDO/FRENTE & $\mathbf{1 9 8 5}$ & $\mathbf{1 9 8 9}$ & $\mathbf{1 9 9 3}$ & $\mathbf{1 9 9 7}$ & $\mathbf{2 0 0 2}$ \\
\hline MNR & $\mathbf{2 6 . 4}$ & 23.0 & $\mathbf{3 3 . 8}$ & 18.2 & $\mathbf{2 2 . 5}$ \\
AP (ADN/MIR) & 28.6 & 22.7 & 20.3 & $\mathbf{2 2 . 3}$ & 3.4 \\
ADN & 8.9 & $\mathbf{1 9 . 6}$ & & 16.8 & 16.3 \\
MIR & & 11.0 & 13.6 & 17.2 & 5.51 \\
CONDEPA & & & 13.1 & 16.1 & 3.1 \\
UCS & 0.7 & 7.2 & 0.1 & 3.7 & \\
IU & 2.2 & 2.8 & & & 20.7 \\
PS-1 & & & & & 20.9 \\
NFR & & & & & 6.1 \\
MAS & & & 2.2 & & 2.7 \\
MIP & & & & & 2.778 .808 \\
MRTKL & 1.728 .363 & 1.573 .790 & 1.731 .309 & 2.177 .171 & \\
\hline LyJ & & & & & \\
\hline Votos válidos & & & & & \\
\hline
\end{tabular}

Cuadro 1. Elecciones nacionales 1985-2002. Fuentes: Dunkerley (2000: 44); Gamarra y Malloy (1995: 432); Yaksic y Tapia (1997); Corte Nacional Electoral www.cne.org.bo. El partido que al final obtuvo la presidencia tiene los porcentajes señalados en negrita. Para una lista de siglas véase el Anexo 1.

institucionalización de la democracia podría haber sido ilusorio en la medida en que, aunque los requisitos mínimos de una poliarquía pueden haberse satisfecho, no se ha logrado una transición posterior hacia un régimen democrático-representativo consolidado. En vez de ello, el proceso parece haberse detenido en lo que él llama "una situación precaria e incierta" (O’Donnell 1999a, 1999b). Con un razonamiento algo similar, Lazarte (2001: 360) ha planteado que, aunque los bolivianos tienden a aceptar la idea de que la democracia es la mejor forma de gobierno, se encuentran poco contentos con la democracia boliviana tal como existe en la realidad. ${ }^{7}$ Por su parte, Whitehead (2001: 12) sugiere que Bolivia es un país con "un conjunto de estructuras y prácticas que ubican a la autoridad fuera del régimen democrático". El presente artículo examina las tensiones reflejadas en el trastorno del sistema de partidos boliviano y muestra que en años recientes el punto de ruptura puede no haber estado muy lejos, aunque hasta el momento se preservó la "institucionalidad". De modo marginal, considera también el tema de las incursiones realizadas por los "partidos étnicos" (Van Cott 2004). Este enfoque (ver Assies y Salman 2004) no es central en el presente ensayo, pero es un aspecto significativo del desorden de la democracia en Bolivia que sí se aborda.

\footnotetext{
7 Revisar también The Economist (17/08/02, pp. 41-42).
}

En segundo lugar, necesitamos reflexionar sobre la significación de la experiencia boliviana para el debate acerca de la consolidación democrática. La redemocratización en Latinoamérica durante los años ' 70 y ' 80 fue ampliamente bienvenida y aplaudida pero también produjo desaliento y desilusión, puesto que sólo muy puntualmente se concretaron algunas esperanzas relacionadas con los procesos de democratización. Ello provocó renovados esfuerzos por conceptualizar la meta de una "auténtica" consolidación democrática (O'Donnell 1999b; Diamond y Plattner 1996; Haynes 2001; Harto de Vera 2000; Schor 2001). Estos esfuerzos muestran diferentes acentos que van desde los enfoques neoweberianos sobre los rasgos religiosos-culturales como sine qua non del capitalismo y la democracia, pasando por el imperativo del imperio de la ley (Schor 2001) y el listado de las precondiciones necesarias en los campos de la alfabetización, la mitigación de las brechas socioeconómicas extremas y la industrialización como la única manera posible de producir la riqueza requerida para sostener la estabilidad democrática, hasta llegar finalmente a los enfoques sobre el nacimiento y arraigamiento de los valores culturales que sostienen el sistema democrático como única forma legítima de resolución de los conflictos societales (Ninou Guinot 2000: 126). Susceptible de probarse empíricamente es la sugerencia hecha por Huntington (1991) de definir la consolidación por la "prueba del doble retorno": si un partido pasa, en elecciones consecutivas, del gobierno a la oposición y luego 
otra vez al gobierno, un sistema político ha pasado la prueba.

Sin embargo, contra una propuesta así de simple la mayoría de los teóricos señala la necesaria correlación entre la evolución de la sociedad y aquella de las instituciones para el logro de la consolidación. Ninou Guinot (2000) aborda la cuestión de la consolidación desde un enfoque procesual, enfatizando el simultáneo "robustecimiento" gradual de las instituciones y procedimientos, y afianzamiento gradual de la legitimidad social de los gobiernos. Alude así a un doble proceso: el fortalecimiento y consolidación institucional están estrechamente relacionados con la confianza creciente en las prerrogativas de estas instituciones y su capacidad para resolver los asuntos de una manera pacífica y equitativa. Dicho de otra manera, se trata de procesos dentro del Estado y en la sociedad que se refuerzan mutuamente. Desde su punto de vista, existen precondiciones específicas para que tal cosa ocurra, no todas las cuales han sido satisfechas en Latinoamérica. En primer lugar, se necesita una aceptación de los resultados electorales así como un respeto de los derechos y la legitimidad de la oposición; lo que otros autores han denominado de "oposición leal" en contraste a la oposición "antisistémica". En segundo lugar, en la actualidad latinoamericana, Ninou Guinot (2000: 145) observa que existe todavía una muy difundida "semilealtad" a la legalidad, tanto entre los grupos gobernantes como entre la oposición. En tercer lugar, la intromisión de las fuerzas armadas en los procesos políticos es una cuestión aún pendiente. Además, los factores socioeconómicos son cruciales. Los altos niveles de pobreza y desigualdad afectan a la larga el apoyo a la democracia. Unos plantean una suerte de disyuntiva, argumentando que mientras que la democracia implica tomar en cuenta los intereses de la mayoría, la gobernabilidad implica tomar en cuenta los intereses de los grupos de poder. Sin embargo, como veremos, el caso boliviano demuestra que la exclusión de la mayoría al final es contraproductiva. Adicionalmente, se necesita un sistema de partidos que sea sólido, es decir, todos los partidos deben respetar los procedimientos democráticos independientemente de su posible frustración electoral o su percepción de amenazas a los intereses de sus representados. Finalmente, se necesita de un Estado capaz para influir en el proceso económico y la distribución de recursos e ingresos a fin de fomentar una confianza en que el Estado pueda impulsar una política "diferente". Al revisar todas estas y algunas otras condiciones previas, Ninou Guinot llega a la conclusión de que varias cosas no están yendo tan mal como podría haberse esperado: el conflicto social es menos violento de lo que fue anteriormente, el rechazo a los sistemas democráticos por los partidos u otros actores políticos ha sido escaso y, aunque el rendimiento económico ha sido débil, se ha podido controlar en gran medida la inestabilidad monetaria. Con todo, la consolidación democrática es un enorme desafío. Desde su punto de vista, la mejor forma de describir la situación actual sería hablando de una "consolidación parcial" (Ninou Guinot 2000: 148).

Con un enfoque similar, Diamond (1996) percibe la necesidad de un proceso de dos vías para sostener la consolidación democrática: por el lado del Estado y el de la sociedad civil. En el ámbito de la sociedad civil, se necesita lograr condiciones previas cruciales para la consolidación democrática: su independencia (pero no alienación) del Estado, su función de fiscalización en relación con éste, y una "vida asociativa plena" (Diamond 1996: 230) que incentive las habilidades democráticas de los ciudadanos, así como la tolerancia, moderación, disposición para llegar a acuerdos y respeto por los puntos de vista opuestos. Adicionalmente, la sociedad civil puede crear canales, distintos a los partidos políticos, para la articulación, agregación y representación de los intereses sociales, con el resultado de una mayor participación, no siendo menor la de nivel local (Diamond 1996: 231). Resumiendo los principales puntos de su análisis, Diamond afirma que:

\section{"[A]l ampliarse la obligación de rendir cuentas (accountability), la capacidad de respuesta, la inclusión, efectividad y, por ende, la legitimidad del sistema político, una sociedad civil vigorosa brinda a los ciudadanos respeto por el Estado y un compromiso positivo con el mismo. Al final, esto mejora la capacidad del Estado para gober- nar..." (1996: 234).}

Sorprendentemente, sin embargo, añade que "el solo factor más importante y urgente en la consolidación de la democracia no es la sociedad civil sino la institucionalización política" (1996: 238). Esto suena contradictorio pero, en la perspectiva de Diamond, tiene sentido porque la adhesión de 
los ciudadanos a la democracia y las leyes depende del desempeño de las instituciones estatales. La consolidación, entendida como "el proceso por el cual la democracia se vuelve tan amplia y profundamente legítima... que es muy improbable su ruptura" (1996: 238), descansa en la capacidad institucional para "asegurar que el gobierno estará en condiciones de formular e implementar algún tipo de políticas, en vez de simplemente ondear por ahí, impotente y sin salidas" (1996: 239). La idea de un proceso de dos vías que se entrelazan emerge nuevamente de estas consideraciones: la consolidación democrática es un proceso en que el control efectivo y la participación capaz de la sociedad, "vigilancia y lealtad" (1996: 239), interactúan con la capacidad de implementación y el vigor institucional del Estado.

Por su lado, Linz y Stepan (1996) hacen la distinción entre los criterios de comportamiento, las actitudes y las estipulaciones constitucionales necesarias para considerar una democracia como "consolidada". El primer punto se refiere a la ausencia de actores de peso que buscan derrocar el proceso democrático; el segundo implica que todos están convencidos de que la democracia es la "mejor vía", y el tercero se refiere a la aceptación del imperio de la ley y los procedimientos democráticos por todos los actores significativos.

En la literatura sobre la consolidación que aquí hemos revisado se específica poco el grado en que la soberanía y participación popular se encuentran delimitadas; tampoco se analiza el proceso a través del cual los criterios enumerados podrían a la larga satisfacerse. Este tiende a ser el problema en muchos de los argumentos sobre el tema: el proceso mediante el cual "los patrones ad hoc de comportamiento orientado hacia la democracia (...) se convierten a la larga en los cánones aceptados" (Haynes 2001: 37) es algo asumido antes que analizado o desglosado en sus partes constituyentes. Haynes distingue entre normas, instituciones y derechos como condiciones previas para la consolidación democrática y trata de establecer el conjunto de factores de los cuales dependen las posibilidades de la consolidación democrática. Estos factores se dividen en políticos, económicos e internacionales. Sin embargo, su elaboración tiende otra vez a caer en un argumento tautológico, como se puede ver claramente en las formulaciones que realiza acerca de estos factores cuando señala a "una cultura política pro-de- mocrática" (ver Salman 2002), "unas formas de sociedad política y civil conducentes a la democracia", "un crecimiento económico sostenido, distribuido más o menos en forma equitativa" y similares (Haynes 2001: 44-49), como condiciones indispensables para lograr una democracia estable.

No es éste el lugar para discutir todas las complejidades de (las condiciones previas y los elementos de edificación de) la consolidación democrática. Lo que podemos aprender de lo anterior es que la lista de "condiciones previas necesarias" para la consolidación tiene un valor analítico pero no ayuda mucho en virtud del hecho de que estas condiciones necesarias son resultados así como requisitos previos en un proceso sin causas y consecuencias unívocas. La "consolidación" sólo se puede validar como un proceso y como un continuo desacuerdo acerca de los contenidos de un orden democrático.

Hemos de argumentar que los resultados de las elecciones bolivianas de 2002 no reflejan simplemente el descontento con el gobierno precedente de Hugo Banzer, el "dictador elegido" (Sivak 2001), cuyo período lo concluyó el vicepresidente Jorge "Tuto" Quiroga después que Banzer fuera diagnosticado con cáncer y renunciara en agosto de 2001. Por cierto, la implosión de ADN y UCS refleja seguramente el descontento con un gobierno específico. Por otro lado, el MIR, que también participó en la "megacoalición", salió relativamente ileso. Nuestro análisis indica que el segundo banzerato y su desgobierno son sólo una parte de la historia.

Proponemos que para entender los resultados de las elecciones de 2002 se requiere un análisis del retorno a la democracia en 1982 y del giro hacia el neoliberalismo en 1985. Las protestas populares que se dieron a partir de 1999 ayudan a explicar buena parte del resultado electoral, y un análisis más minucioso revela que no solo estuvieron dirigidas contra un gobierno particular ${ }^{8}$, sino también contra un "modelo de desarrollo" impuesto en 1985. Al mismo tiempo, ellas revelan las ca-

\footnotetext{
8 Aunque las protestas fueron alimentadas sin duda por el hecho de que el gobierno de Banzer se caracterizó por el hábito vigente de la politiquería, el fraude sofisticado, pugnas al interior de las facciones políticas, y cosas por el estilo.
} 
racterísticas y problemas del régimen político formalmente democrático de Bolivia y sugieren que el Estado ha pretendido, de modo sistemático y probablemente deliberado, excluir a grandes sectores de la población del control y la participación genuinos. Esto señala un déficit de "consolidación", especialmente en relación con la "obligación de rendir cuentas, capacidad de respuesta, inclusión, efectividad y, por tanto, legitimidad del sistema político" (Diamond 1996: 234).

En el siguiente acápite presentaremos primero una revisión muy sucinta de la historia política de Bolivia desde 1982, el año en que la democracia fue restituida. Resaltamos la "doble transición" de Bolivia. Al tiempo que el país se volvía formalmente democrático, desde 1985 adoptaba también un marco de política económica neoliberal y, después de 1993, una serie de reformas de "segunda generación" fueron introducidas para completar las medidas de ajuste adoptadas en 1985. En la segunda parte del acápite nos concentramos en el segundo gobierno de Banzer, de 1997 a 2002, y mostramos su incapacidad para impedir que las condiciones económicas siguiesen empeorando. Esta ineptitud, combinada con la arrogancia y corrupción desvergonzada, características del segundo banzerato, constituyó el trasfondo del creciente descontento social que analizaremos en la tercera parte de este artículo. Allí revisaremos algunos de los episodios más importantes de conflicto social. La forma en que el gobierno respondió a estas protestas es reveladora del "déficit de representación" que caracteriza al Estado formalmente democrático de Bolivia. El descontento reprimido frente a una clase política indiferente, inepta y además totalmente corrupta (Salman 2000a) explica el creciente apoyo a los políticos "antisistémicos". Luego, esbozamos el desarrollo del sistema de partidos boliviano y, particularmente, damos cuenta del clima político en que algunos de los protagonistas de las protestas sociales, tales como el líder del MAS, Evo Morales y del MIP, Felipe Quispe, se convirtieron en alternativas atractivas para el electorado. A éste le sigue un acápite final donde buscamos conectar nuestra revisión del desarrollo de la política boliviana y el sistema de partidos con algunas de las nociones teóricas sobre la consolidación democrática que hemos introducido anteriormente.

La mayor parte de este texto fue escrito en los meses inmediatamente posteriores a las eleccio- nes de 2002. En febrero de 2003, Bolivia se convirtió de nuevo en escenario de enfrentamientos dramáticos entre movimientos de protesta y las fuerzas del "orden". En vista de estos acontecimientos hemos añadido un epílogo que describe los desafíos que enfrenta el actual gobierno y las decisiones que llevaron a la violenta convulsión de febrero de 2003.

\section{Bolivia en transición: Una revisión}

Cuando el primer Banzerato (1971-78) se había cerrado con la renuncia de Hugo Banzer, Bolivia ingresó a un proceso de transición democrática parecido a una montaña rusa con caídas abruptas como las dictaduras de Alberto Natush Busch y Luis García Meza (Whitehead 1994). Al final, en 1982 se había instalado un gobierno sostenido por la coalición de centro-izquierda Unidad Democrática Popular (UDP). Estuvo presidida por Hernán Siles Zuazo, uno de los veteranos de la Revolución de 1952, quien tuvo que enfrentar la tarea de administrar una economía virtualmente en bancarrota y satisfacer las demandas populares reprimidas. El gobierno de la UDP intentó relanzar el modelo económico nacional-revolucionario instalado en 1952 pero este intento terminó en fracaso rotundo. La inflación se convirtió en hiperinflación y el descontento social estaba que hervía. Finalmente, con un dramático gesto de renuncia, Siles se hizo a un lado y convocó a elecciones un año antes de terminar su mandato constitucional. Le sucedió otro veterano de la Revolución, Víctor Paz Estenssoro (1985-1989), el Jefe del MNR quien fue elegido presidente por el Congreso con el apoyo de ADN, el partido fundado por Hugo Banzer después de renunciar a su período dictatorial. Ambos MNR y ADN firmaron un Pacto por la Democracia. A fines de agosto de 1985, el gobierno de Paz Estenssoro introdujo una Nueva Política Económica (NPE), a través del Decreto 21060, que consistió en un duro tratamiento de shock; decreto que se convertiría en blanco emblemático de las protestas sociales del final de los ' 90 .

Entre muchas otras medidas, los despidos masivos de mineros y otros empleados públicos, llevados a cabo a pesar de las protestas, marcaron la derrota de la antaño poderosa Central Obrera Boliviana (COB). Un efecto adicional de la liberalización comercial fue la inundación de los mercados bolivianos con mercancías importadas 
baratas, lo cual determinó el cierre de muchas fábricas grandes y medianas. Debe señalarse que el relativo éxito macroeconómico de la NPE estaba relacionado con el hecho de que el paquete económico facilitó el lavado de narcodólares. La cocaína se convirtió en el principal producto de exportación del país (Laserna 1997: 177).

Jaime Paz Zamora (MIR), también nuevamente con la ayuda de la ADN de Banzer, fue presidente de 1989 a 1993. Su gobierno continuó en lo esencial las políticas de ajuste pero la nueva coalición mostró poca coherencia en sus políticas económicas; la ausencia de crecimiento económico le restó apoyo popular. Además, la corrupción era generalizada e, internacionalmente, el gobierno se volvió sospechoso de estar involucrado con el narcotráfico. ${ }^{9}$

Las elecciones de 1993 resultaron en un gobierno del MNR encabezado por Gonzalo "Goni" Sánchez de Lozada (1993-97), acompañado de Víctor Hugo Cárdenas como su vicepresidente gracias a una sorprendente alianza entre el MNR y uno de los pequeños partidos kataristas, el MRTK-L (Albó 1994). ${ }^{10}$ Cárdenas se había transformado en un líder indígena más intelectual y por tanto más digerible para el electorado mestizo, que abanderó la causa del pluriculturalismo y la multietnicidad. Esta alianza era sorprendente no sólo por el matrimonio derecha/izquierda, sino también porque el MNR había tradicionalmente negado o simplemente ignorado el elemento étnico en la política boliviana. El decreto del reemplazo de la palabra "indio" por aquella de "campesino", después de la Revolución de 1952, había sido obra suya y, de modo más general, el partido representaba una doctrina más nacionalista que multicultural. Pero el MNR había cambiado, se había abierto a las ideas en torno a la descentralización, participación y multicultura$\operatorname{lidad}^{11}$, y estaba listo para implementar una "se-

9 En 1997, uno de los hombres fuertes del MIR, Oscar Eid Franco, fue sentenciado a cuatro años de prisión por complicidad con narcotraficantes. Retiraron la visa de ingreso de Jaime Paz Zamora a los Estados Unidos, sin embargo, la misma le fue renovada en mayo de 2001.

10 Para una revisión de movimientos de los pueblos indígenas en Bolivia, ver también Assies (2000) y Van Cott (2000).

11 Sin embargo, la adhesión a la multiculturalidad parece haber sido poco profunda. En alguna medida, fue un artificio gunda generación" de reformas neoliberales que, entre otras cosas, apuntaba a la modernización del aparato estatal. Las reformas iniciadas por el gobierno de Sánchez de Lozada se enmarcan dentro del cuadro que Hale (2002) ha caracterizado como "multiculturalismo neoliberal"; un multiculturalismo que acepta un paquete mínimo de derechos culturales pero igualmente rechaza de manera vigorosa las implicancias más profundas del multiculturalismo y de las demandas indígenas.

Después de las elecciones, el gobierno del MNR firmó un "pacto de gobernabilidad" con la UCS, mientras que, por otra parte, llegaba a un acuerdo con el pequeño MBL, asegurándose así un suficiente respaldo parlamentario. La conformación de esta coalición entre un núcleo de tecnócratas neoliberales ligados al MNR y reformistas del MBL y MRTK-L dio lugar a una mezcla de políticas orientadas por un "reformismo social neoliberal". Entre las reformas destacables estaba la "capitalización", la variante boliviana de privatización de las empresas públicas que fueron convertidas así en empresas mixtas donde el 50\% de sus activos había sido vendido en el mercado de capitales; una medida que además estuvo ligada a la reforma del sistema de pensiones. Otra reforma importante fue introducida mediante la Ley de Participación Popular de 1994. Esta ley implicaba una amplia reestructuración y descentralización de la estructura político-administrativa del país a través de una revalorización del que, hasta entonces, había sido un intrascendente nivel municipal de gobierno. La participación de los gobiernos locales en el total de la inversión pública subió de aproximadamente 9\% en 1994 hasta cerca de $25 \%$ a finales de la década de 1990 , mientras que la participación del gobierno central bajó de $65 \%$ a $29 \%$. Al mismo tiempo, esta ley pretendió incorporar a la población indígena de Bolivia mediante el reconocimiento de las autoridades tradicionales y el otorgamiento de estatus legal a las comunidades campesino-indígenas y

para atraer electores que darían su voto al MIR o CONDEPA. La designación de Víctor Hugo Cárdenas se debió, en buena medida, al resultado de un estudio de mercado en el ámbito político. La dedicación de los neoliberales al multiculturalismo se encuentra inmersa en sus enfoques sobre la descentralización y un tipo particular de participación, enfoques que a menudo son contrarios a las aspiraciones de los movimientos de los pueblos indígenas (Calla 2000). 
los pueblos indígenas, así como a las organizaciones vecinales (Calla 2000). La reforma del sistema educativo se orientó hacia una educación participativa, intercultural y bilingüe. En 1996, se introdujo una nueva legislación agraria y forestal. La reforma de la Constitución en 1994 no solamente reconoció la composición multiétnica de la sociedad boliviana sino que allanó el camino para las reformas de los sistemas judicial y electoral. La reforma promulgada en 1996 creó 68 distritos uninominales para la elección de una parte de los representantes en la Cámara de Diputados. Aunque la reforma pretendía fortalecer el actual sistema de partidos y reforzar su control de la política local, tuvo el efecto imprevisto de abrir un resquicio para el ingreso de nuevos partidos. Este efecto se vio claramente en las elecciones de 2002. Pero antes, se dio el retorno de Banzer a la Presidencia.

\section{El segundo "Banzerato"}

El gobierno de "Goni", acusado de ser "duro", preparó el terreno para el gobierno de la megacoalición de Banzer que asumió el poder en 1997 careciendo de cualquier programa definido. En la primera sesión de su gabinete realizada el 16 de agosto, al inicio de su mandato de cinco años ${ }^{12}$, el presidente propuso lo que llamó los "Diez Mandamientos" de su gobierno: adhesión estricta a la ley, respeto al ciudadano, prohibición al uso indebido de la propiedad estatal, austeridad, disciplina, sobriedad, sentido de autocrítica, modestia, convivencia democrática, honestidad (Sivak 2001: 74-75). En los hechos resultó que la mayoría de estos mandamientos fueron incumplidos. El vicepresidente Jorge Quiroga asumió la tuición las políticas económicas y asistió a las reuniones con las agencias financieras multilaterales. Al interior, los socios de la megacoalición disputaban por cuotas de poder, anticipando otro rasgo persistente de ese período de gobierno.

Todos los planes del gobierno para "reactivar" la economía no lograron revertir las tendencias de depresión económica, en parte debido a que el gobierno perdía credibilidad rápidamente y era

12 La reforma constitucional de 1994, ratificada en febrero 1995, había alargado el período presidencial de cuatro a cinco años. lento en ejecutar sus planes. La agudización de los conflictos sociales, la "guerra del agua" en Cochabamba (sobre la cual hablaremos más adelante) y los bloqueos de caminos por los cocaleros y campesinos de muchos lugares del país en abril y "septiembre negro", empeoraron las cosas. Aparte de que las protestas populares habían caracterizado al 2000, a fin de año los empresarios, especialmente del oriente, se pusieron crecientemente intranquilos, e inclusive, empezaron a cuestionar al modelo económico y amenazar con la "resistencia civil". En vista de este nuevo desafío, el gobierno empezó un diálogo con ese sector y, en marzo de 2001, llegó a un acuerdo en el que se prometieron medidas complementarias, la mayor parte en el área de reprogramación de deudas y reducción de impuestos. Los analistas observaron que las medidas podrían ser bastante beneficiosas para un pequeño grupo, pero fracasaban en encarar las cuestiones fundamentales como el empleo o las serias dificultades de los pequeños productores; los intereses de la mayoría fueron sacrificados en beneficio de los grupos de poder. Además, el acuerdo incluía cláusulas sobre la habilitación de los campesinos para que puedan utilizar sus tierras como garantía, una propuesta planteada insistentemente por los agroempresarios y duramente rechazada por las organizaciones campesinas.

Los millones de bolivianos que sufrieron las severas consecuencias de la crisis y las medidas incapaces de contrarrestarla nunca tuvieron una oportunidad de participar en algún diálogo sobre las causas y los remedios para la situación que se atravesaba en Bolivia. A medida que la crisis se profundizaba y los ingresos reales de la mayor parte de la población se hundían, surgieron pedidos de renuncia del presidente Banzer, entre otros del líder del MNR, Sánchez de Lozada. Banzer rechazó vehementemente la idea y estaba decidido a terminar su período de cinco años. No iba a ser así. En junio de 2001, le diagnosticaron cáncer y, a pesar de sus intentos iniciales de aferrarse al poder, decidió bajarse de la silla presidencial en agosto de 2001.13 Jorge "Tuto" Quiroga, quien por entonces escasamente hablaba con

13 Por supuesto, su muerte relanzó los debates acerca de su significación en la reciente historia boliviana, en la medida en que fue presidente dos veces, primero como dictador y, muchos años después, como presidente constitucional. La 
Banzer, ascendió a la presidencia y anunció su Plan de Doce Meses para reactivar la economía, que era básicamente un resumen y condensación de las políticas implementadas hasta entonces (reprogramación de deudas y fortalecimiento de las instituciones financieras, distribución de los beneficios de la capitalización, pago del BOLIVIDA -que sustituyó al Bonosol- y la devolución de los aportes al fondo de vivienda, más la reprogramación de las finanzas municipales) a ser cubiertas con el gasto acelerado de los ingresos por exportaciones de gas al Brasil y complementadas mediante la incorporación de microempresas en el mantenimiento de la red de carreteras a fin de generar empleos temporales.

\section{Convulsiones sociales y diálogo en medio de las balas}

Las protestas no habían estado ausentes en los primeros años del gobierno de Banzer. Sin embargo, el año 2000 fue un punto de inflexión. Revisaremos aquí el conflicto más destacado que explotó ese año, en la medida en que fue un indicador del déficit del sistema de partidos establecido en Bolivia y el fracaso de la mediación política -un "déficit de representación"- y ayudará a explicar los resultados de las elecciones de 2002. Después de examinar este conflicto "ejemplar" sobre el agua en Cochabamba ${ }^{14}$, nos abocaremos a varios otros actores contestatarios significativos. Por razones de espacio, dejaremos de lado los bloqueos organizados principalmente por los campesinos indígenas del altiplano y los conflictos por la tierra y los territorios indígenas en los llanos del oriente y, en su lugar, nos iremos a los conflictos sobre la erradicación de cocales. Tanto el asunto de los conflictos y actores que abordamos como aquellos que omitimos, forman historias paralelas: son encendidas por otras protestas, se desarrollan sincrónicamente o en parte se yuxtaponen. Al mismo tiempo, compiten por la primacía, por la atención de los gobiernos, por la capa-

mayor parte de las apreciaciones no fue positiva. Para muchos, Banzer terminó como un presidente que será recordado por promover la corrupción y prebendalismo a niveles inauditos y por no haber dejado ningún legado político que valga la pena conmemorar en el transcurso de su "repechaje" democrático.

14 La "guerra del agua" se analiza en detalle en Assies (2001 y 2003) y en Nickson y Vargas (2002). cidad de movilización y a veces se enfrentan entre ellas sobre demandas específicas y sobre prioridades. Pero su similitud se encuentra en su acusación contra un Estado que perciben como "autista" en relación a los problemas que ponen sobre el tapete.

\section{La Guerra del Agua en Cochabamba}

Desde hace varias décadas el agua ha sido un bien escaso en Cochabamba y ha provocado disputas entre el Municipio y las áreas rurales que la rodean que se vieron afectadas por la perforación de pozos profundos para proveer de agua a la ciudad. Desde hace décadas también había una solución en los papeles: el proyecto MISICUNI que traería agua a la región desde el área de recolección de Misicuni, a través de un sistema de túneles y acueductos, y de paso generaría electricidad. En las mentes de muchos cochabambinos, MISICUNI había adquirido un aura mágica en el transcurso de los años y en varias ocasiones se movilizaron para presionar por su implementación. Sin embargo, se trataba de un proyecto costoso y, según el Banco Mundial (1999), un "elefante blanco". De todos modos, las soluciones alternativas propuestas por el gobierno de Sánchez de Lozada habían sido rechazadas. Hacia el final de su gobierno, Sánchez de Lozada propuso una puja abierta por MISICUNI y vincularla con la privatización de la ineficiente empresa municipal de agua SEMAPA, a objeto de incrementar su rentabilidad futura. Este proceso de puja empezó durante el gobierno de Banzer. Algunas empresas transnacionales se mostraron inicialmente interesadas pero retrocedieron después de examinar las condiciones y sólo un consorcio, Aguas del Tunari, continuó mostrando interés. Las autoridades dieron brazo a torcer frente a la mayoría de las condiciones planteadas por el consorcio, lo que significó reducir drásticamente el proyecto inicial, flexibilizar los términos del contrato y permitir un duro incremento en las tarifas de agua, hasta que, en septiembre de 1999, el contrato fue firmado.

Por otro lado, el gobierno tramitó en noviembre una ley de agua potable y saneamiento básico en el Congreso, aunque una Ley General de Aguas que debía proporcionar el marco para esa legislación secundaria era controvertida y todavía estaba siendo debatida. La nueva ley introdujo un sistema de concesiones por 40 años para las áreas 
en que se esperaba que la provisión de agua fuera rentable. El otorgamiento de tales concesiones sería llevado a cabo por una Superintendencia, cual legado del gobierno de Sánchez de Lozada que, siguiendo los lineamientos de las agencias multilaterales, había introducido estas entidades para reglamentar aquellos sectores con tendencia a constituir monopolios naturales. Las Superintendencias funcionan como autarquías y dispensan al Estado de involucrarse directamente en la administración de los recursos. Se esperaba que en 41 ciudades la provisión de agua sería rápidamente transferida a concesionarios privados. De hecho, la ley de agua potable y saneamiento básico legalizó de este modo el contrato con el consorcio de Aguas del Tunari.

La oposición al contrato provino primero de los sectores de clase media como los ingenieros, abogados y algunos ambientalistas quienes organizaron un Comité para la Defensa del Agua y la Economía Popular. Entre otras críticas, ellos denunciaban que el contrato permitía una dura elevación de las tarifas que podría alcanzar a $180 \%$ en algunos sectores de la población. La oposición se hizo mayor cuando al Comité se unió el sindicato de los trabajadores fabriles, los bien organizados regantes del valle de Cochabamba y los comités urbanos de abastecimiento de agua que manejaban pozos cooperativos, ya que el sistema de SEMAPA sólo cubría parte del área urbana. ${ }^{15} \mathrm{La}$ nueva agrupación adoptó el nombre de Coordinadora para la Defensa del Agua y la Vida.

Cuando a principios de enero de 2000 las facturas de agua empezaron a llegar a manos de la población, incorporaban en efecto drásticos incrementos en las tarifas de hasta $150 \%$ en algunos casos. De hecho, a la población se le estaba haciendo pagar por adelantado las promesas de mejoras futuras en el abastecimiento de agua. Al mismo tiempo, se llegó a saber que el contrato permitía que Aguas del Tunari instale medidores en los pozos perforados por las cooperativas y los propietarios privados. Entonces empezó un movimiento de protesta en que la Coordinadora y el

15 Aparte de tales pozos, a menudo perforados con la ayuda de ONGs o la Iglesia, los camiones cisternas son también importantes para el abastecimiento del agua a los sectores más pobres de la población, los mismos que con seguridad, son un negocio rentable.
Comité Cívico, intentando este último recuperar terreno tras haber celebrado el contracto con Aguas del Tunari en 1999, rivalizaban por la hegemonía. Esto derivó en una serie de protestas que enfrentó una dura represión por parte de un gobierno que estaba más preocupado con el clima de inversiones que con la economía popular. Violentas batallas callejeras sacudieron la ciudad a comienzos de enero y febrero hasta alcanzar el clímax en los primeros días de abril, cuando las protestas llegaron a involucrar prácticamente a toda la población que salió a bloquear, inclusive las calles de barrio. Los enfrentamientos con las fuerzas armadas ocasionaron muchos heridos y fue muerto un adolescente, muy probablemente por un francotirador del ejército vestido de civil. ${ }^{16}$

Los enfrentamientos en Cochabamba estuvieron entre las razones por las que el gobierno declaró un Estado de Sitio el 8 de abril. En la víspera, la Iglesia y otros mediadores habían organizado un encuentro entre la Coordinadora, el Comité Cívico, autoridades municipales y una delegación de Ministros a realizarse en la Prefectura de Cochabamba. Sin embargo, para consternación de los mediadores, en vez de que arribaran los ministros llegó un contingente policial que arrestó a la delegación de la Coordinadora, la cual fue puesta en libertad al día siguiente. En todo el país, los líderes de las protestas en curso fueron arrestados siendo 22 de ellos deportados a San Joaquín, la "Liberia" boliviana en el Departamento tropical del Beni.

Los arrestos no sólo fracasaron en dispersar las movilizaciones, también tuvieron un efecto contrario porque dieron nuevo impulso a las protestas que, finalmente, obligaron al gobierno a ceder. El contrato con el Consorcio Aguas del Tunari fue cancelado, la ley de agua potable y saneamiento básico fue sustancialmente modificada con una rápida gestión ante el Congreso, y el abastecimiento de agua en la ciudad fue devuelto a SEMAPA con un nuevo Directorio que incluía "independientes" ligados a la Coordinadora. La Coordinadora proclamó que después de 15 años de derrotas del movimiento popular había revertido la tendencia

16 El gobierno negó que francotiradores hubiesen estado trabajando, incluso a despecho de las escenas de video que mostraban claramente lo contrario y que fueron difundidas por la red de televisión P.A.T. 
y obtenido una victoria sobre el neoliberalismo y el capital transnacional. Más tarde buscó transformarse en un movimiento de oposición, la Coordinadora de Movilizaciones Unica Nacional (COMUNAL), asumiendo como su tarea varios reclamos de usuarios de servicios públicos así como asuntos laborales. Esto sugiere el modo en que el vacío dejado por la desarticulación de la $\mathrm{COB}$ podría ser llenado por un nuevo tipo de organizaciones que ya no están enraizadas estrictamente en el lugar de trabajo sino también en el barrio (Kruse 2002).

Varios aspectos del contexto de la guerra del agua deberían tomarse en cuenta. En primer lugar, la manera en que el gobierno ignoró las primeras protestas, recurriendo entonces a una represión dura y, al final, firmando acuerdos que no está dispuesto a llevar a cabo; una dinámica que Laserna (1999) ha caracterizado como "negociación forzada".

En segundo lugar, y relacionado con lo primero, debería indicarse que el gobierno negó legitimidad a la Coordinadora como interlocutor válido. En vez de ello, en el curso de las protestas el gobierno buscó negociar con el Comité Cívico, el mismo que -aunque nominalmente de base amplia- representa en gran medida al sector empresarial y a algunos notables. Esta actitud fue justificada señalando los artículos de la Constitución boliviana que definen solamente a los partidos políticos y grupos cívicos con "personalidad reconocida" como los canales legítimos de participación. La posición del gobierno respecto a esta cuestión es sintomática de la falla inherente al sistema. Tanto la legislación como las actitudes y posiciones asumidas por sus funcionarios manifiestan una grieta entre el sistema político y las voces y demandas de la sociedad. El menosprecio a la legitimidad de todas las objeciones a las decisiones gubernamentales que no estén formuladas por entidades oficialmente reconocidas, como pretende el oficialismo, delata el carácter excluyente de la política. A su vez, los manifestantes descubren que la única manera de hacer que el gobierno "pise tierra" es presionándolo con medios que rebasan los canales formalmente reconocidos. Esta rutina es ilustrativa de una regularidad en que la falta de respuesta del sistema político socava la consolidación democrática, debido a que bloquea un elemento fundamental de tal régimen: la representación de las preocupaciones de la sociedad y la heterogeneidad en la esfe- ra de la deliberación política y toma de decisiones.

La Coordinadora no tenía "personería jurídica reconocida" pero contaba con amplio apoyo y legitimidad en la población. Este es un caso que ejemplifica lo que Habermas (1992: 237) ha denominado "la opinión pública como una ficción de la ley constitucional". Se ignora y puede reprimir a la opinión pública que no está canalizada según los preceptos constitucionales. Sin embargo, el gobierno se vio finalmente obligado a negociar con la Coordinadora como resultado de las protestas masivas y prolongadas, una dinámica que encaja en el concepto de "negociación forzada" propuesto por Laserna.

En tercer lugar, se debería tomar en cuenta que al final se llegó a una resolución negociada del conflicto a través de la mediación del Arzobispo Tito Solari, la Asamblea Permanente de Derechos Humanos de Bolivia (APDHB) y la Defensoría del Pueblo. Los partidos políticos no jugaron ningún papel, lo que apunta a un "déficit de representación".

En cuarto lugar, el movimiento no estuvo confinado al área urbana; incluía a los regantes del valle de Cochabamba. El movimiento campesino a nivel nacional añadió el rechazo a la ley de saneamiento básico a su lista de demandas; consideraba que la legislación sobre el agua constituía una amenaza. Esto incluía al sistema de las Superintendencias que, al operar con criterios de rentabilidad, tienden a favorecer a la empresa privada $^{17}$ y no están sujetas al control popular. La alternativa propuesta para el caso del agua es un Consejo Nacional de Agua que incluya a representantes de los consumidores. Por último, la rabia contra el contrato con Aguas del Tunari por parte de los manifestantes, incluidos no sólo los sectores populares, sino los de clase media, no se debió solamente al contenido del contrato, sino también al engaño sobre la elevación de tarifas y, más allá de todo aquello, a la falta de transparen-

\footnotetext{
17 Otro caso puntual es la Superintendencia de Recursos Forestales que otorgó concesiones forestales que se yuxtaponen a los territorios indígenas que estaban en proceso de su reconocimiento. El caso fue remitido para su consideración por la ILO que, en 1999, emitió una serie de recomendaciones para que Bolivia cumpla con la Convención 169 sobre derechos de los pueblos indígenas.
} 
cia en las negociaciones en un contexto de amplia corrupción gubernamental. ${ }^{18}$

La "guerra del agua" fue el más destacado de los acontecimientos de protesta y choques que el gobierno de Banzer enfrentó. Sin embargo, es una historia inmersa en todo un conjunto de historias similares, algunas ocurridas en forma (parcialmente) paralela, y otras manifestándose después o antes de estos acontecimientos específicos. Sin poder abordar aquellos temas, cabe señalar que se trata de una coyuntura de protestas que incluyó las de los campesinos del altiplano liderados por Felipe Quispe ${ }^{19}$, de los cocaleros encabezados por Evo Morales y el movimiento de los pueblos indígenas del oriente, para mencionar algunas. Quispe y Morales, a quienes presentaremos más adelante, se convirtieron en figuras políticas en el curso de esa serie de conflictos. El gobierno los pintó como agitadores "irresponsables" y "extremistas", pero como ya mencionamos, en 2002 el electorado no coincidía con esta percepción. Antes de abocarnos a esos temas, esbozaremos los acontecimientos relacionados con otro ámbito de conflicto endémico: la coca.

\section{Los cocaleros y el Movimiento al Socialismo}

Como se mencionó anteriormente, el partido que salió segundo en las elecciones del 2002 tiene sus

18 Un último elemento que vale la pena mencionar es que, en 2002, el Consorcio Aguas del Tunari, a través de su preeminente "empresa matriz" Bechtel, llenó un pedido de compensación ante un tribunal del Banco Mundial, por las utilidades que no había podido realizar, recurriendo para ello a los Tratados Bilaterales sobre Inversiones o BITs. Por el hecho de que Holanda tiene tal acuerdo BIT con Bolivia, el proceso ha sido tramitado a través de la extensión de correo "P.O.Box" que tiene la empresa en Holanda.

19 Sólo para ilustrar un acontecimiento durante el largo período de protestas: las protestas indígeno-campesinas condujeron a un violento enfrentamiento en la localidad de Achacachi, el 9 de abril de 2000, ocasionando la muerte de dos campesinos y un capitán del ejército. Pretendiendo mostrar a los habitantes aymara de Achacachi como irracionalmente violentos y crueles, el Ministro de Defensa Jorge Crespo y fuentes del ejército afirmaron que el Capitán Omar Téllez no sólo había sido golpeado hasta morir sino que también había sido descuartizado y sus ojos arrancados, afirmaciones que más tarde fueron negadas por el director del hospital local y por la Defensora del Pueblo, Ana María Romero, quien denunció las acciones abusivas de los militares y señaló que el Capitán Téllez había sido el primero en disparar a matar (La Prensa 5/06/00). raíces en las organizaciones de los cultivadores de coca del Chapare, en su mayor parte quechuahablantes. El cultivo de la coca en esta región no es muy antiguo. Creció espectacularmente rápido durante el primer régimen de facto de Banzer (1971-78) y en la década de los '80. Mientras que los militares estaban entonces fuertemente involucrados en el circuito de la cocaína, no existe evidencia de que los productores campesinos estén involucrados en el crimen organizado. A pesar de no ser una región de cultivo de coca tradicional, resultó ser una población combativa. Con el liderazgo de gente como Evo Morales, los agricultores constituyeron un grupo bien organizado, en una situación suficientemente desesperada como para estar dispuestos a defender ferozmente su sustento, conseguido hace poco después de haber inmigrado a la región a consecuencia de los bajos rendimientos agrícolas en el altiplano y los despidos masivos en la minería a partir de 1985, que los obligaron a desarrollar otra estrategia de supervivencia.

Uno de los pocos "logros" reivindicados por el gobierno de Banzer ha sido la considerable reducción de la producción de coca en Bolivia. Considerando que en 1997 se estimaba que unas 38.000 hectáreas tenían cultivos de coca, en 2001 las estimaciones se encontraban en un rango de 3.000 a 6.000 ha. En los seis años anteriores, la "guerra contra la coca" había provocado más de 50 víctimas fatales y 500 heridos, mientras que cerca de 400 personas fueron detenidas en base a la Ley 1.008 sobre la coca y sustancias controladas de 1988, una ley que contradice absolutamente la vigencia de los derechos humanos. ${ }^{20}$

Inicialmente, en octubre de 1997, los cocaleros del Chapare habían decidido cooperar con la erradicación voluntaria, pero las cosas cambiaron cuando en enero de 1998 el gobierno hizo público su Plan Dignidad. El Plan tenía cuatro "pilares": el desarrollo alternativo, la prevención y rehabilitación, la erradicación de la coca ilegal y redundante, y la interdicción. Para el período 1998-2002 se presupuestaron US\$ 952 millones de los cuales US\$ 700 estarían destinados al desarrollo alternativo. A principios de febrero, en el contexto de la nueva estrategia y los acuerdos bi-

20 Para una discusión sobre el desarrollo de la política antidrogas, véase Laserna (1996 y 1998). 
laterales con los Estados Unidos, Banzer autorizó tácitamente la participación "ampliada" de las fuerzas armadas en la guerra contra las drogas. El Chapare organizó la resistencia al Plan. Las condiciones del diálogo se deterioraron cuando en marzo el gobierno anunció que la compensación económica por la erradicación de una hectárea de coca sería reducida de US\$2.500 a US\$ 1.650 . En abril, la represión de los bloqueos de carreteras en el Chapare provocó sus primeras víctimas entre los campesinos y la región fue crecientemente militarizada con el pretexto de que habría grupos armados operando allí. La militarización vino de la mano con el abuso a los derechos humanos, las detenciones injustificadas, la tortura, violación de mujeres y el robo por parte de los militares. Entretanto, las políticas del desarrollo alternativo produjeron unas carpetas más lujosas y grandes titulares de periódicos en lugar de beneficios tangibles para los campesinos. Hasta el año 2000, los enfrentamientos habían reclamado las vidas de 11 campesinos y seis policías.

Cuando en septiembre de ese año, los bloqueos de caminos liderados por Felipe Quispe empezaron en el altiplano, los cocaleros aprovecharon la ocasión para presionar por sus propias demandas $\mathrm{y}$, en particular, protestar contra la intención del gobierno de construir tres nuevos cuarteles militares en el Chapare. Aparte de mejores condiciones para la comercialización de los productos del desarrollo alternativo, también exigieron que se les permitiera cultivar un "cato" $\left(1.600 \mathrm{~m}^{2}\right)$ de coca por familia. Mientras que en las primeras semanas de octubre una serie de otros conflictos terminaron en negociaciones, el conflicto en el Chapare se prolongó e intensificó. Varios policías y erradicadores fueron emboscados y asesinados; el gobierno acusó a Evo Morales de ser el autor intelectual de los crímenes y pidió el retiro de su inmunidad parlamentaria, aunque nunca pudo proporcionar pruebas sólidas que respalden su acusación. ${ }^{21}$ Una de las líderes cocaleras que había sido arrestada con esos cargos tuvo que ser nuevamente liberada cuando se hizo absolutamente claro que ella no pudo haber estado en el lugar del crimen. Por su parte, Morales sugirió que las muertes bien podrían haber sido provocaciones que justifiquen la militarización, una versión que

21 Tampoco se ha podido nunca probar los presuntos vínculos de Morales con la mafia de la cocaína (Albó 2003). adquirió credibilidad cuando en noviembre de 2001 se hizo evidente que una fuerza especial irregular paralela de entre 1.000 a 2.000 "mercenarios" habían sido reclutados para llevar a cabo una "guerra sucia" contra las drogas.

Mientras tanto el gobierno, en diciembre de 2000, había declarado haber logrado su meta de "coca cero" en el Chapare. Ello fue inmediatamente refutado y dio lugar a bastantes especulaciones sobre cuánto quedaba todavía. De este modo, el "Plan Dignidad" terminó en disputas interminables sobre cuánto se había erradicado, cuánto quedaba y cómo estaban funcionando los programas de cultivos alternativos y compensación a los agricultores; el Plan había costado un número variable de víctimas en cada año de implementación y, finalmente, se convirtió en "erradicación perpetua", en la medida en que las 600 ha que habían quedado en cierto momento se convertían en 6.000 ha al siguiente mes. Violentos enfrentamientos ocurrieron nuevamente en los últimos meses de 2001; en noviembre, cinco campesinos murieron durante la represión a los bloqueos y se denunció también la violación de 30 mujeres por parte de las fuerzas represivas. El Ministro de Información Mauro Bertero comentó que esta supuesta violación fue "producto de la intolerancia de los cocaleros". 22

En ese momento, bajo la presión de la Embajada de Estados Unidos, el presidente Quiroga intensificó las políticas anticoca y nombró a un "zar antidrogas”. El gobierno se empeñó tercamente en su obsesión fundamentalista con la meta de "coca cero" en el Chapare y, en base a dos decretos de noviembre de 2001, decidió controlar todos los transportes de hoja de coca y cerrar su mercado legal en Sacaba el 15 de enero de 2002. ${ }^{23}$ La provocación no tardó en conducir a una con-

22 Mientras la reacción del ministro es otra muestra de insensibilidad escandalosa de la clase política, cabe señalar que los hechos denunciados por la diputada Helen Hayes (MNR) no fueron confirmados ni denunciados oficialmente por los cocaleros.

23 El mercado de Sacaba es más bien poco significativo en comparación con el mercado de La Paz, pero es un importante punto de salida para algunas toneladas de coca legal que producen los campesinos del Chapare. Debido a las políticas de erradicación, la cantidad de hoja de coca vendida se redujo en un $90 \%$ y las ventas cayeron desde cerca de Bs. 20 millones en 1997 hasta Bs. 6 millones en 2001. 
frontación violenta durante los siguientes días (Pulso 18-24/01/02). Veinticinco vehículos de la agencia de control del narcotráfico fueron quemados, tres campesinos y dos soldados murieron en los enfrentamientos y pocos días después se encontró a dos soldados que habían sido cruelmente asesinados.

Fue otro asesinato en circunstancias oscuras, el mismo que proporcionó al presidente Quiroga una nueva oportunidad para demandar el retiro de la inmunidad parlamentaria de Evo Morales. Después de un proceso abreviado a cargo de la "comisión de ética", 104 de los 130 miembros de la Cámara de Diputados votaron a favor de la "separación definitiva" de Morales, lo que significaba su virtual "erradicación" del escenario político. Morales no sólo perdió su inmunidad sino que también su mandato popular fue anulado. El ex ministro y miembro de la Cámara Baja Fernando Kieffer, él mismo inmune a cualquier posibilidad de ser procesado por varios casos de corrupción, fue claro en señalar que el objetivo era eliminar a la expresión política y sindical del movimiento cocalero (Pulso 25-31/01/02).

Aquella mayoría que había votado en contra de Morales no esperaba que su decisión tuviese mayores consecuencias; "nada, absolutamente nada ocurrirá", afirmó Fernando Kieffer. No pudo haber estado más equivocado. Después de cuatro años de Banzerismo, a los del gobierno y la mayor parte de la clase política se los percibía, y por muy buenas razones, como enteramente corruptos y arrogantes que desprecian a la mayoría de la población. Cuando Morales fue expulsado del Parlamento, la gente se sintió profundamente ofendida y humillada por una clase política que había armado un proceso fraudulento en contra de uno de ellos y, además, sintió que se atrevieron a hacerlo porque Morales era un indio. El desprecio racista de la clase gobernante se volvió contra ella misma como un boomerang. Los sectores del movimiento campesino normalmente divididos cerraron filas. La CSUTCB -la confederación sindical campesina cuyo liderazgo había sido fuertemente disputado en el pasado por varias tendencias y no menos actualmente por los entornos de Morales y Quispe, siendo este último su principal dirigente en ese momento- convocó al bloqueo de caminos en su Congreso de Sucre, los cocaleros de Yungas hicieron lo propio y los del Chapare marcharon hacia Cochabamba donde Morales se encontraba en huelga de hambre en la sede del Sindicato de Trabajadores Fabriles. Ellos acamparon en los predios de la Universidad de San Simón desde donde marchaban diariamente a la plaza principal para saludar a Morales. Una vez más la ciudad se convirtió en el escenario de violentas confrontaciones entre los manifestantes y las fuerzas policiales. Fernando Kieffer tuvo que admitir el 6 de febrero que "[el] país está viviendo una situación dramática que se vuelve más complicada minuto a minuto" (Pulso 8-14/02/02).

Dos días más tarde el gobierno y Evo Morales llegaron a un acuerdo. Los puntos básicos eran que los decretos sobre el secado y transporte de la hoja de coca serían suspendidos y que un nuevo esquema para su comercialización legal debía ser acordado entre ambas partes. Los derechos políticos y sindicales de Evo Morales serían respetados, además de que la Iglesia y la APDHB iniciarían un trámite de apelación ante el Tribunal Constitucional para anular la expulsión de Morales de la Cámara de Diputados. El Gobierno también atendería las demandas de varios otros movimientos y respetaría los acuerdos a los que se había arribado con Felipe Quispe (La Prensa 9/02/02).

Una pregunta que hizo Morales fue: ¿cuánto había pagado la embajada norteamericana para obtener todos los votos "éticos" en contra suya? En efecto, aparte de la rabia popular contra el gobierno y la clase política más el descontento con las políticas neoliberales a las que Morales siempre se había opuesto con vehemencia, la injerencia de la embajada norteamericana en la política boliviana supuso una ayuda extraordinaria para catapultarlo a su victoria electoral. Su ascenso en los sondeos preelectorales había preocupado tanto al embajador norteamericano que unos pocos días antes de las elecciones advirtió a los bolivianos -después de haber afirmado que se trataba de un país libre e independiente- que no votaran por Morales si no querían perder el apoyo de Estados Unidos. ${ }^{24}$ Sus declaraciones elevaron a Morales desde el cuarto hasta el segundo lugar y cuando los resultados de las elecciones empezaron a confirmar su abrumadora victoria, Morales se burló

\footnotetext{
24 Para un análisis sugerente sobre la creciente vinculación de doble vía entre los intereses geopolíticos y los motivos detrás de la "ayuda al desarrollo", ver Duffield (2001).
} 
indicando que no habría podido conseguir un mejor jefe de campaña electoral.

\section{Sistémicos y antisistémicos: Un sistema de partidos trastornado}

Los ejemplos seleccionados de protestas que hemos descrito fueron las fuerzas decisivas en la mira de devastación del espectro de partidos establecidos. Los partidos emergentes presentan un desafío al sistema tal como éste solía funcionar, y reflejan las voces de los sectores que ya no aceptaban más el engaño de la emisión del voto tal como lo habían conocido, lo cual dista mucho, por supuesto, de la apropiación de un lugar reconocido en el espectro de partidos o de haber desarrollado la fuerza para corregir sustancialmente el déficit del sistema de partidos.

Los partidos tradicionales establecidos en Bolivia y su accionar se pueden resumir, si lo formuláramos cínicamente, bajo el título de "poder, corrupción y mentiras". La lista de casos es demasiado larga como para contarla rápidamente. A pesar de algunos intentos de aminorar en algo el "déficit de representación" que caracteriza al sistema de partidos boliviano (Tapia y Toranzo 2000), los resultados de las elecciones del 2000 y el ascenso de las fuerzas llamadas antisistémicas sugieren que la renovación ha sido muy poco exitosa. Esto ayuda a explicar el surgimiento de los "anti-sistémicos". Ya hemos discutido sobre Evo Morales y mencionado a Felipe Quispe, el "Mallku". Ellos transformaron su capacidad de movilización en partidos: el MAS y el MIP. Los elementos más destacables de sus éxitos electorales en junio de 2002 son dos: el hecho de que a pesar de que estos partidos fueron estigmatizados como extremistas, subversivos, antidemocráticos e "irracionales" les fuera tan bien, y el hecho de haber utilizado crecientemente el argumento étnico, y no haber dudado en utilizar la polarización entre "poderosos blancos-mestizos" e "indígenas sometidos y explotados", algo considerado tabú en las décadas anteriores de discurso cada vez más "políticamente correcto" en la política boliviana. Mientras que la mayoría de analistas políticos del país llegaron a la conclusión de que estos elementos habrían de perjudicar a estos partidos en obtener una parte significativa de la votación, los acontecimientos se dieron de otro modo. La contradicción entre la improbabilidad "lógica" de su éxito y el hecho de haberlo logrado de todos modos, es indicativa de cuánta credibilidad ha perdido el sistema.

El gobierno de Banzer simboliza este proceso. Su intento desesperado por subrayar su vocación democrática, después de haber sido elegido presidente con el olor del "antiguo dictador" todavía sobre él, lo alejó, por lo general, de maniobras como disolver el parlamento o decretar cosas que prohíbe la Constitución. El Estado de Sitio que decretó una vez, costó varias vidas pero fue efímero; se volvió rápidamente evidente que no se acercaría a ninguna solución a la amenaza planteada por el descontento mediante la suspensión de los derechos civiles y políticos. Al ser confrontados con la opción entre una represión dura de tipo dictatorial y el retorno a la mesa de negociaciones, las autoridades finalmente optaron por esta última alternativa. Por lo general, el gobierno frecuentemente terminó cediendo a las peticiones de los movilizados y, posteriormente, incumpliendo lo acordado, reflejando el patrón de la "negociación forzada".

Sin embargo, la presidencia de Banzer fue manchada por varias decisiones debatibles en relación con la preservación de todos los estándares democráticos. Más de una vez el gobierno recurrió a los militares para "restaurar el orden" en los muchos casos de acciones de protesta. Y durante su período, decenas de personas murieron en los enfrentamientos entre las fuerzas policiales o militares y los manifestantes, la mayor parte en la región del Chapare. Por último, aunque no menos importante, los mecanismos vigentes y nuevos de la corrupción financiera, la manipulación política y la impunidad de los políticos que esquivan la ley o sus obligaciones tributarias, no pueden ser vistas como respaldo a normas democráticas "limpias". A este ambiguo currículo de servicio en el orden del respeto a los cánones de la democracia, debe añadirse el fracaso total para mejorar el desempeño económico y las políticas sociales. En conjunto, estos rasgos no modificaron y muy probablemente incluso exacerbaron una herencia de profunda desconfianza respecto al sistema político por parte de una abrumadora mayoría de la población (ver Salman 2000b). Mucha gente siente que existe un gran abismo entre sus preocupaciones y las de los políticos.

Miles de bolivianos sienten que sus intereses y las consecuencias de las medidas políticas sobre 
sus medios de sustento casi nunca se reflejan en las deliberaciones políticas. Ellos tienen la sensación de que no existe una alternativa política en la cual depositar una firme confianza para la defensa y expresión de sus problemas. Curiosamente, los lugares comunes del discurso como "hablar el lenguaje de la gente común", "no ser un político más sino alguien del pueblo", han marcado las recientes contiendas electorales pero nunca se materializaron en un acceso efectivo al sistema político por parte de aquella "gente común". El sistema de partidos como sistema de mediación entre la sociedad y el Estado sólo se ha deteriorado aún más en años recientes (Gamboa 2001: 102). Situaciones como esta llevaron a que Ninou Guinot (2000: 146) sugiriera que Latinoamérica se caracteriza por tener partidos fuertes aunque un débil sistema de partidos; los partidos monopolizan el campo de la representación y descalifican o cooptan las formas organizativas alternativas pero, al mismo tiempo, la combinación de estas características dan como resultado un mecanismo de mediación totalmente defectuoso. El sentimiento de no tener ningún acceso a través de los mecanismos electorales institucionales y formales ${ }^{25}$ alentó la costumbre boliviana de resolver los conflictos políticos y sociales mediante vías extraparlamentarias. Para la democracia esto significa que:

25 La confianza en los políticos y partidos es tradicionalmente precaria en Latinoamérica (ver Camp 2001), pero alcanza niveles bajísimos en Bolivia: según un sondeo de 1990, $77 \%$ de los bolivianos expresaron su convicción de que los partidos no trabajaron por el bien del país sino que defendieron meramente sus intereses de grupo (Gamboa 2001: 101; ver también Berthin Siles y Yáñez 1999: 37-44). Según The Economist (17/08/02), en la mayoría de los países de la región, el respaldo de la población al funcionamiento de la democracia en sus países se incrementó de 1996 al 2002; pero en Bolivia esto ocurrió sólo levemente. Con todo, más del $70 \%$ de los encuestados expresaron una parcial o total insatisfacción. De todos modos, como lo muestra el sondeo en cuyos resultados se basan estas conclusiones, el apoyo a la democracia como tal, como el sistema político preferible a otros, se incrementó, lo cual justifica el comentario de The Economist acerca de "un rayo de leve esperanza para los demócratas" (17/08/02, pp. 41). Además, vale la pena mencionar que el desprecio hacia los partidos políticos en Bolivia se ha incrementado (los partidos califican diez de un total de 40 puntos posibles), así como el descreimiento respecto a que las privatizaciones hubiesen beneficiado al país. En cuanto a hostilidad hacia la privatización, a Bolivia sólo le sobrepasan Argentina, Paraguay y Uruguay. "[al] haber escasa sensación de una "interfase" positiva entre las estructuras partidarias y las identidades sociales, cuando ya la mayor parte de la población recibe poca atención en el proceso de reforma económica, el fracaso en incorporarla políticamente representa una amenaza al avance democrático" (Domingo 2001: 157)

Esta tendencia se ha prolongado e inclusive intensificado en los últimos años, debido a varios factores. En primer lugar, la tradicional falta de confianza en los políticos y partidos, y las consignas y promesas que encarnan, se ha acentuado debido a las políticas recientes en las cuales el Estado se desligó de responsabilidades y tareas antaño formalmente asumidas. Hoy en día los políticos son vistos como aquellos que mercantilizan lo que, al menos en principio, debería constituir su razón de ser: asumir la tarea de desarrollar el país y proporcionar bienestar a todos los bolivianos. Considerando que antes "sólo" el cumplimiento de lo que se consideraba eran las tareas del Estado solía quedar insatisfecho, hoy esto ocurre también con el papel del Estado en el cuidado del bienestar de la nación a través de una intervención activa, puesto que las políticas post"nacional-desarrollistas" descartan esa función estatal. Sin embargo, la gente siente que las consecuencias de las políticas de privatización y desregulación, y la falta de acceso a la política, le afecta en varios grados y formas en su vida cotidiana. La percepción ciudadana de abandono, a la que se añaden sus sospechas bien fundadas sobre corrupción y falta de confiabilidad, da lugar a la "naturalización"de protestas radicales, feroces y desconsideradas, las que en los últimos años se han convertido en la cuna de los políticos y organizaciones políticas "antisistémicas".

En segundo lugar, las tendencias económicas recientes exacerbaron la segregación tradicional y no contribuyeron a la integración social y cultural. La brecha tradicional se profundizó abismalmente y convirtió en sospecha absoluta. La representación se debilitó y, simultáneamente, los niveles de vida se deterioraron. Como resultado, los sectores desposeídos reciben con una profunda desconfianza, e interpretándola como una amenaza, cualquier propuesta o medida proveniente "desde arriba". Esto alienta las demandas y posturas que muestran poca empatía con puntos de vista e intereses de los oponentes. Una especie de "encierro en su propia verdad" que afecta ambas partes 
perjudica al diálogo y negociación (Calderón y Szmukler 2000: 330). Al mismo tiempo, existe una terca incapacidad para identificar a los compañeros de infortunio y articular intereses compartidos y alianzas posibles (Paris Pombo 1990: 65).

En tercer lugar, las iniciativas de descentralización y la promoción de la participación local que Banzer heredó de "Goni", las cuales habían contado al comienzo con el beneficio de la duda entre amplios sectores de la población, quedaron varadas por los engaños, sabotaje y peleas mezquinas, contribuyendo de este modo a los ya intensos sentimientos de estar siendo impedidos de utilizar los canales formales e institucionalizados para hacer escuchar sus voces. En este sentido, estos procesos reflejaron la persistencia de la "democracia limitada" (Haynes 2001: 14-15), y posiblemente respalden su afirmación aun más temeraria de que "la democracia limitada en Latinoamérica no necesariamente es una etapa temporal o transitoria, sino que muy bien podría ser una forma de gobierno duradera que mezcla un grado considerable de democracia con un grado considerable de autoritarismo" (Haynes 2001: 79). O en los términos de Crabtree y Whitehead (2001: 218) (a pesar de que su conclusión general sobre el estado de la situación respecto a la democracia en Bolivia es ligeramente más positiva que la nuestra): “...los rasgos fuertemente oligárquicos, clientelistas y provincianos (...) reducen la profundidad a la que la democracia representativa puede llegar a enraizarse". Nosotros sugerimos que la falta de legitimidad de la "autoridad legal" debería tomarse en cuenta y complementarse con la noción de "ficciones de ley constitucional" propuesta por Habermas (1992: 236), ya que los movimientos de protesta fueron descalificados con el argumento de que carecían de credenciales legales, a pesar de su legitimidad entre la población. En consecuencia, un fuerte sentimiento de que "ellos sólo entienden el argumento de la fuerza" se consolidó tanto entre los tradicionales luchadores (trabajadores, mineros, maestros) como entre las nuevas constelaciones de manifestantes (consumidores de agua, cocaleros, rentistas, transportistas y otros).

El déficit democrático evolucionó hacia una falta de correspondencia estructural entre las percepciones, preocupaciones e intereses de amplios sectores de la sociedad y el Estado. Los partidos y las autoridades son incapaces de expresar la lec- tura que realiza la sociedad de las medidas políticas y sus efectos sociales, y de canalizar las incertidumbres y demandas de la población. A los ojos de mayorías abrumadoras, las instituciones estatales han estado poco inclinadas a intervenir de una forma que "marque una diferencia" o bien son incapaces de hacerlo. En vez de ello, tienden a quedar absorbidas en pugnas por cuotas de poder y siguen reclutando sus cuadros de los sectores de población poco representativos mientras, al mismo tiempo, persisten en recibir a los nuevos contendientes políticos con maniobras engañosas a través de legislación autodefensiva de los partidos políticos y otras medidas ad hoc si fuera necesario. Esto hizo que el tema subyacente de las elecciones de 2002 fuera el mal funcionamiento del sistema de partidos como tal, hasta convertirse en el mensaje de las nuevas voces, idiomas y vestimentas en las cámaras legislativas.

Se trata de un cambio significativo, pero está lejos de ser uno decisivo. Como se dijo anteriormente, las protestas siguieron siendo dispersas y mayormente reactivas. La mayor parte de las acciones y manifestaciones no mostraron un agrupamiento de visiones y propuestas coordinadas o siquiera emparentadas por parte de los manifestantes. Muchos incidentes fueron medidas ad hoc, aisladas y desencadenadas por situaciones fortuitas, a menudo tenían un aspecto oportunista, y no estaban orientadas a converger. Los "antisistémicos" están lejos de actuar, por tanto, como "sistémicos alternativos" y tampoco actúan todavía como la voz coherente de aquellos que les dieron su voto en rechazo a las tradicionales prácticas de exclusión.

De cualquier modo, en sus discursos, los dirigentes y voceros insisten en la culpabilidad del capital internacional, las políticas de ajuste estructural y la privatización añadiendo la explotación y discriminación estructuradas en términos raciales. Y a pesar de la fragmentación, las protestas no fueron cuestión del azar. Al revisar las motivaciones, temas y coyunturas, se vuelve evidente que las protestas expresaban la rabia y ansiedad provocadas por las consecuencias de un conjunto de medidas políticas promovidas por las políticas de reestructuración y ajuste que sufrió la población, en un contexto de incapacidad e ineficacia institucionales y pugnas políticas mezquinas. Esta combinación de transformaciones económicas que debilitaron las condiciones de subsistencia de la 
población y de intentos de cambios políticos que fracasaron en lograr una participación real debería considerarse como responsable de la persistente ola de protestas que el gobierno de Banzer tuvo que enfrentar, y del éxito electoral de la antipolítica.

\section{Epílogo}

El segundo gobierno de "Goni" Sánchez de Lozada enfrenta un fuerte vendaval. Encara vientos en contra en lo económico, luchas políticas internas y una oposición política que expresa una crítica intransigente a su legitimidad.

En lo económico, el gobierno enfrenta varias condiciones adversas que escapan a su control: la crisis en Argentina afectó todavía más el comercio exterior, llevó a las importaciones ilegales a bajar los precios contra los que la industria nacional no es capaz de competir y provocó un retorno de la población migrante que exacerba el desempleo. El desempeño poco seguro del Brasil en lo económico y monetario, y el actual aflojamiento económico en el planeta, también afectan las perspectivas de exportación del país. Y la complicada puesta en vigencia del Acuerdo de Preferencias Arancelarias Andinas ${ }^{26}$ tampoco alienta las perspectivas de una expansión de las exportaciones.

Los asuntos que se encuentran, en principio, al alcance del gobierno, parecen igualmente problemáticos. La reactivación económica será difícil de obtener. Casi con cinismo, considerando los actuales indicadores de pobreza, The Economist Intelligence Unit en su Country Report de agosto de 2002, informa que la inflación probablemente seguirá por debajo del $3 \%$ "en tanto la demanda interna sólo se incrementará modestamente". La misma fuente predijo también que el nuevo gobierno

"tendrá que reconciliar las ofertas electorales de incrementar la inversión del sector público con la presión del FMI y los acreedores internacionales para que consolide las finanzas públicas después del desfase fiscal de los últimos 18 meses".

En una conferencia de prensa inmediatamente posterior a su elección, "Goni”" afirmó que "éste

26 APTA; ver The Economist Intelligence Unit Country Report, agosto de 2002. será un gobierno de mucha intervención en la economía, para hacerla funcionar...". Se trata de una afirmación bastante poco convencional proviniendo de un reputado neoliberal, lo cual sirve para subrayar los dilemas que enfrenta el gobierno. El gobierno está muy consciente de que, en Bolivia, la desconfianza hacia la globalización, y más en particular hacia el FMI (Fondo Monetario Internacional) como un representante de la globalización con poderes para imponer políticas monetarias y económicas que afectan negativamente a las mayorías de la población, es enorme. Por eso, el gobierno se muestra reticente a aplaudir su rol públicamente.

Lo más probable es que en la mayoría de los sectores estatales, como educación, los ministerios, las fuerzas armadas y policía, y otros, los salarios seguirán siendo bajos (aunque los funcionarios de mayor jerarquía hayan recibido incrementos anteriormente, no obstante los tiempos adversos). Con toda probabilidad, las oportunidades de empleo difícilmente se incrementarán, debido a que el FMI no estará muy dispuesto a aprobar nuevos gastos del sector público para los proyectos de infraestructura anunciados por "Goni". Y, probablemente, los ingresos fiscales por la explotación del gas y otros recursos naturales no serán suficientes para darle al gobierno mayores perspectivas.

Al preparar este trabajo, no podíamos habernos imaginado que apenas siete meses después de su posesión, "Goni" enfrentaría una ola de violencia e insurrección sin precedentes que habrían provocado 30 víctimas fatales y según algunas fuentes incluso más de 50. El 12 de febrero de 2003 una serie de sucesos fatales desembocaron en una fuerte balacera en el mismo centro de La Paz, que obligó al presidente a retirar una medida impositiva clave, cambiar casi completamente su gabinete e intentar desesperadamente la recuperación de su autoridad. Esto ocurrió después de que estos sucesos habían terminado en muchas víctimas fatales y casi una guerra abierta entre dos instituciones del orden principales -las fuerzas armadas y la policía- al punto de que la propia supervivencia política de su gobierno se había vuelto dudosa.

Esto es lo que ocurrió ${ }^{27}$ : obligado por un considerable déficit fiscal y la necesidad de obtener un

\footnotetext{
27 Agradecemos el apoyo de Hernando Calla en reconstruir
} los acontecimientos descritos aquí. 
nuevo préstamo del FMI condicionado a la reducción de dicho déficit, el gobierno de Goni diseñó una medida impositiva que se resumía en un impuesto a la renta del $12.5 \%$ para los salarios por encima de Bs. 880, lo que equivale aproximadamente a US\$ 115. Desde el primer momento, la propuesta provocó una amplia protesta, por su falta de consideración de un impuesto progresivo y por hacer caer -"una vez más"- la factura del desgobierno en las espaldas de los bolivianos pobres. Los sectores que iban a ser afectados por la medida eran los empleados del sector público y las grandes empresas; la mayoría de gente que trabaja en la economía informal sólo sería afectada indirectamente.

Entre los descontentos más conspicuos estaba la policía. Sus efectivos se amotinaron y dejaron de controlar las calles el 12 y 13 de febrero -mientras las mismas se llenaban de gente que salía a protestar en las inmediaciones del centro paceñorechazando la medida impositiva e insistiendo en un aumento de sueldos que habían estado solicitando durante un largo tiempo. Como es normal en situaciones de protesta en las calles, el palacio presidencial en la Plaza Murillo estaba resguardado por un pequeño contingente de policía militar. En la Plaza, la policía verde olivo recibió la compañía de "[c]abreados de toda índole, militantes de la exclusión, trotskistas y demás fauna propia de la rebelión..." (Pulso 14-20/02/03); poco antes, estudiantes de secundaria habían aprovechado el desconcierto de la policía militar para arrojar piedras a la fachada del Palacio de Gobierno, rompiendo la mayoría de las ventanas. Ellos habían llegado allí exigiendo el retiro del director del Colegio Ayacucho y también gritaban consignas de rechazo a la política del gobierno en general y contra el "impuestazo" en particular. La verdadera refriega empezó una vez que los escolares se habían retirado, después que soldados adolescentes barrieran las piedras y vidrios rotos que los estudiantes habían dejado a las puertas de Palacio y avanzaran hasta la mitad de la plaza. Al fracasar la mediación por parte de los representantes de Derechos Humanos entre los policías amotinados y el Ministro de Defensa, a consecuencia de la intempestiva aparición de efectivos de la patrulla 110 con gran ruido de sirenas en una de las esquinas de la Plaza Murillo, los militares responden abriendo fuego. Las primeras víctimas fueron policías que se encontraban en torno al palacio presidencial. A su vez, los policías abrieron fuego sobre el Palacio causando bajas y heridos entre oficiales y soldados que lo resguardaban.

En medio del caos, el presidente fue evacuado y no volvió a aparecer sino algunas horas más tarde en un video difundido por un canal de TV privado (el canal estatal había dejado de emitir su señal) donde, no obstante la desazón reflejada en los rostros, intentaba mostrar haber negociado un alto al fuego entre los comandantes de las instituciones armadas que se habían enfrentado y que aparecían dándose la mano.

Mientras tanto el desborde social había cundido más allá de cualquier posibilidad de control, la muchedumbre, que se había reunido en la plaza y los alrededores, atacó las dependencias de la Vicepresidencia, además de los Ministerios de Desarrollo Sostenible y de Trabajo, saqueando equipos, muebles y materiales, a los que luego prendieron fuego, para luego proseguir y hacer lo mismo con las oficinas de la Alcaldía y la Aduana Nacional en El Alto, y terminar asaltando varios centros comerciales, particularmente, del centro paceño y alteño. Este saqueo se prolongó hasta el día siguiente.

Sorprendentemente, los dos grupos de oposición al gobierno más poderosos y consistentes no fueron los protagonistas en estos acontecimientos. De cualquier modo, el MAS, liderado por Evo Morales, no dudó en pedir la renuncia del presidente inmediatamente después de los sucesos del 12 y amenazó con nuevas medidas de protesta. Felipe Quispe se unió a ellos en esta demanda y amena$\mathrm{za}$, aunque su relación con Morales se mantuvo siempre tensa. Sin embargo, ambos fueron reactivos y no proactivos durante los acontecimientos del 12 de febrero y los inmediatamente posteriores.

Su reacción se sumó a los otros desafíos que enfrenta el gobierno: los rentistas protestaban contra los montos minúsculos que reciben, los consumidores contra los incrementos en las tarifas de los servicios básicos y las privatizaciones, los maestros de escuela contra el nivel de sus salarios, los empresarios contra la falta de reactivación de la economía, los cocaleros acababan de tener negociaciones para una pausa temporal en la erradicación, y los campesinos del altiplano todavía 
seguían esperando la entrega de una serie de tractores, como una concesión simbólica por parte del gobierno antes de proceder al manejo más sistemático de un conjunto de reivindicaciones del sector campesino. Al interior de estos grupos y entre ellos, las afinidades eran y todavía son frágiles, la cooperación es débil o inexistente, y las identidades se desplazan desde lo étnico, pasando por lo socioeconómico y gremial, hasta lo regional y nacional, en configuraciones cambiantes y prioridades relativas.

El gobierno retiró la medida impositiva y, en los siguientes días, se removió casi a todo el gabinete. Esta medida estuvo acompañada del mensaje del presidente a la nación pidiendo calma y comprensión para la necesidad de adoptar políticas de austeridad. En su alocución, subrayó que su gobierno estaba dando el ejemplo al reducir el número de ministerios y, él mismo al renunciar a su salario. Sin embargo, los últimos informes de marzo de 2003 sugieren que las amenazas de protesta continúan y los partidos de la coalición, mientras se daba la reestructuración del gabinete, ingresaban a una pelea por cuotas de poder como si nada hubiese ocurrido.

El impacto en el país fue enorme. La prensa lamentó unánimemente el número sin precedentes de muertos en un solo día, desde que la democracia fuera restituida, y diagnosticó la incapacidad gubernamental para mantener el orden y el monopolio de la violencia debido al amotinamiento dentro de las instituciones que supuestamente deben garantizarlo. Los comentarios de prensa insistieron en la urgencia de tomar medidas innovadoras que impidan la desintegración y anomia en el país. El prestigio del gobierno recibió un golpe devastador y, según los informes de algunos observadores, la inseguridad reinó en las calles, en los círculos de gobierno, entre los empresarios e inversionistas, y en todo el espectro de los partidos políticos.
Las protestas no pueden ser menospreciadas como "convulsión" y saqueo no político, aunque sin duda estuvieron presentes elementos asaltantes y oportunistas. Aun en la situación actual de grupos de presión no coordinados e inclusive enfrentados, hay una clara señal de que el actual manejo de la crisis socioeconómica por parte del actual gobierno, así como del anterior, no logra ninguna tolerancia entre amplios sectores de la población y de que este rechazo alcanza niveles de descrédito de la legitimidad del gobierno como tal.

Por el momento, es difícil imaginar un plan de gobierno coherente aunque algunos comentarios de prensa han dado pistas sobre los problemas fundamentales que enfrenta la coalición. A esto debe añadirse la notoria ineficiencia actual en la implementación de políticas y la estructura de servicios públicos. Los resultados de esta nueva fase de desintegración del Estado y la sociedad en el contexto de lo que se esperaba serían las "nuevas reglas del juego" en la escena parlamentaria, quedan todavía por verse. A primera vista, los acontecimientos anticipan un mayor deterioro del proceso democrático que podría buscar nuevamente una salida violenta que desafíe a las autoridades políticas y termine, esta vez con el apoyo de voces "subversivas" en los círculos "oficiales", ilegitimando aún más la validez del ordenamiento legal en Bolivia. Para prevenir este escenario, se necesita algo más que medidas políticas. Se requiere una transformación de los mecanismos subyacentes que condujeron a la actual polarización y convulsiones, y es posible que a la larga la nueva configuración en el Parlamento pueda jugar un papel en este proceso. Pero está por verse si la nueva presencia parlamentaria de aquellos anteriormente excluidos podrá anunciar en algún momento la transición hacia una democracia que los bolivianos encuentren valioso defender.

Agradecimientos A Hernando Calla por su traducción. 


\section{REFERENCIAS CITADAS}

ALBO, X., 1994. And from Kataristas to MNRistas? The surprising and bold alliance between aymaras and neoliberals in Bolivia. En Indigenous peoples and democracy in Latin America, D. Van Cott (Ed.), pp. 5581. St. Martin's Press, Nueva York.

2003. Andean ethnicity today: Four aymara narratives from Bolivia. En Imaging the Andes - Shifting margins of a marginal world, T. Salman y A. Zoomers (Eds.), pp. 226-248. Aksant, Amsterdam.

ASSIES, W., 2000. Multiethnic constitutionalism, territories and internal boundaries: The bolivian case. En Fronteras: Towards a borderless Latin America, pp. 319-348. CEDLA, Amsterdam.

2001. David vs. Goliat en Cochabamba: Los derechos del agua, el neoliberalismo y la renovación de la protesta social en Bolivia. Tinkazos 8: 106-131.

2003. David fights Goliath in Cochabamba: Water rights, neoliberalism and the renovation of social protest in Bolivia. Latin American Perspectives 30 (3): 14-36.

ASSIES, W. y T. SALMAN, 2004. A deconsolidating democracy? - The 2002 Bolivian elections in perspective. Global Review of Ethnopolitics (en prensa).

BERTHIN SILES, G. y E. YAÑEZ, 1999. ¿Qué sabemos sobre el desarrollo democrático boliviano?, Punto Cero, La Paz.

CALDERON, F. y A. SZMUKLER, 2000. La política en las calles. CERES / Plural / UASB, La Paz.

CALLA, R., 2000. Indigenous peoples, the law of popular participation and changes in government: Bolivia 19941998. En The challenge of diversity: Indigenous peoples and reform of the State in Latin America, W. Assies, G. van der Haar y A. J. Hoekema (Eds.), pp. 77-94. Thela Publishers, Amsterdam.

CAMP, R. (Ed.), 2001. Citizen views of democracy in Latin America. Pittsburgh Press, Pittsburgh.

CRABTREE, J. y L. WHITEHEAD, 2001. Conclusions. En Towards democratic viability. The bolivian experience, J. Crabtree y L. Whitehead (Eds.), pp 216-234. Palgrave, Houndmills, Basingstoke y Hampshire.

DIAMOND, L., 1996. Toward democratic consolidation. En The global resurgence of democracy ( $2^{\text {nd }}$ edition), L. Diamond y M. F. Plattner (Eds), pp 227-240. The John Hopkins University Press, Baltimore.

DIAMOND, L. y M. F. PLATTNER (Eds.), 1996. The global resurgence of democracy ( $2^{\text {nd }}$ edition). The John Hopkins University Press, Baltimore.

DOMINGO, P., 2001. Party politics, intermediation and representation. En Towards democratic viability. The bolivian experience, J. Crabtree y L. Whitehead (Eds), pp. 141-159. Palgrave, Houndmills, Basingstoke y Hampshire.

DUFFIELD, M., 2001. Global governance and the new wars. The merging of development and security. Zed Books, Londres y Nueva York.

DUNKERLEY, J., 2000. Warriors and scribes. Verso, Londres y Nueva York.

GAMARRA, E. A. y J. MALLOY, 1995. The patrimonial dynamics of party politics in Bolivia. En Building democratic institutions; Party systems in Latin America, S. Mainwaring y T. R. Scully (Eds.) pp. 399-433. Stanford University Press, Stanford.

GAMBOA ROCABADO, F., 2001. Itinerario de la esperanza y el desconcierto. Ensayos sobre política, sociedad y democracia en Bolivia. Muela del Diablo, La Paz.

HABERMAS, J., 1992. The structural transformation of the public sphere; An inquiry into a category of Bourgeois Society. Polity Press, Cambridge.

HALE, C., 2002. Does multiculturalism menace? Governance, cultural rights and the politics of identity in Guatemala. Journal of Latin American Studies 34: 485-524.

HARTO DE VERA, F., (Ed.), 2000. América Latina: Desarrollo, democracia y globalización. Trama Editorial / CECAL, Madrid.

HAYNES, J., 2001. Democracy in the developing world. Africa, Asia, Latin America and the Middle East. Polity Press, Cambridge.

HUNTINGTON, S., 1991. The third wave: Democratization in the Late Twentieth Century. University of Oklahoma Press, Norman.

INE, 2001. Anuario Estadístico 2001. Instituto Nacional de Estadística, La Paz.

KRUSE, T., 2002. Transición política y recomposición sindical: Reflexiones desde Bolivia. En Ciudadanía, cultura política y reforma del Estado en América Latina, M. Calderón, W. Assies y T. Salman (Eds.), pp. 219-251. El Colegio de Michoacán, Instituto Federal Electoral de Michoacán, Zamora.

LASERNA, R., 1997. 20 (mis)conceptions on coca and cocaine. Clave, La Paz.

_ 1998. De la duda a la confusión; coca y lucha antidrogas entre 1993 y 1997. En Las reformas estructurales en Bolivia, J. C. Chávez (Ed.), pp. 381-447. Fundación Milenio, La Paz.

LAVAUD, J. P., 1991. L'instabilité politique de l'Amerique Latine: Le cas de la Bolivie. L'Harmattan, IHEAL, París. 
LAZARTE, J., 2001. Entre dos mundos: La cultura política y democrática en Bolivia. En Política e instituciones en las nuevas democracias latinoamericanas, I. Chersky e I. Pousadela (Comps.), pp. 309-366. Paidós, Buenos Aires, Barcelona y México D. F.

LINZ, J. y A. STEPAN, 1996. Problems of democratic transition and consolidation: Southern Europe, South America and postcommunist Europe. The John Hopkins University Press, Baltimore.

MAINWARING, S. y T. R. SCULLY (Eds.), 1995. Building democratic institutions; Party systems in Latin America. Stanford University Press, Stanford.

MILENIO, 2000. Informe de milenio sobre la economía $\mathrm{N}^{\circ}$ 9. Fundación Milenio, La Paz.

NICKSON, A. y C. VARGAS, 2002. The limitations of water regulation: The failure of the Cochabamba concession in Bolivia. Bulletin of Latin American Research 21 (1): 99-120.

NINOU GUINOT, C., 2000. Transición y consolidación democrática en América Latina. América Latina: Desarrollo, democracia y globalización, F. Harto de Vera (Comp.), pp. 123-151. Trama Editorial / CECAL, Madrid.

O’DONNELL, G., 1999a. Delegative democracy. En Counterpoints; Selected essays on authoritarianism and democratization, G. O'Donnell, pp. 159-173. University of Notre Dame Press, Notre Dame.

-1999b. Illusions about consolidation. En Counterpoints; Selected essays on authoritarianism and democratization, G. O’Donnell, pp. 175-194. University of Notre Dame Press, Notre Dame.

PARIS POMBO, M. D., 1990. Crisis e identidades colectivas en América Latina. Plaza y Valdez Editores, México D. F.

SALMAN, T., 2000a. The magic frontier: Casting a spell on formal borders. Smuggling in Bolivia. En Fronteras: Towards a borderless Latin America, pp. 181-201. CEDLA, Amsterdam.

2000b. Politico-cultural models and collective action strategies. The pobladores of Chile and Ecuador. En The collective and the public in Latin America, L. Roniger y T. Herzog (Eds.), pp. 192-216. Sussex Academic Press, Brighton y Portland.
2002. Clavar gelatina contra la pared. La "cultura política" entre sondeo y excusa mayor. Iconos - Revista de FLACSO sede Ecuador 15: 20-30.

SCHOR, M., 2001. The rule of law and democratic consolidation in Latin America, http://darkwing.uoregon. edu/ caguirre.

SIVAK, M., 2001. El dictador elegido. Biografía no autorizada de Hugo Banzer Suárez, Plural, La Paz.

TAPIA, L. y C. TORANZO, 2000. Retos y dilemas de la representación política, PNUD-Bolivia Cuadernos de Futuro 8, La Paz.

VAN COTT, D. L., 2000. Friendly liquidation of the past: The politics of diversity in Latin America. University of Pittsburgh Press, Pittsburgh.

2004. Institutional change and ethnic parties in South America. En Latin American politics and society (en prensa).

VAN LINDERT, P. y O. VERKOREN, 1994. Bolivia in focus, a guide to the people, politics and culture. LAB, Londres.

WHITEHEAD, L., 1994. La democratización frustrada en Bolivia, 1977-1980. En Transiciones desde un gobierno autoritario 2; América Latina, G. O'Donnell, P. C. Schmitter y L. Whitehead (Comps.), pp. 79-111. Paidós, Barcelona, Buenos Aires y México D. F.

2001. The viability of democracy. En Towards democratic viability. The Bolivian experience, J. Crabtree y L. Whitehead (Eds), pp. 3-20. Palgrave, Houndmills, Basingstoke y Hampshire.

YAKSIC, F. II y L. TAPIA, 1997. Bolivia; Modernizaciones empobrecedoras, desde su fundación a la desrevolución. Muela del Diablo, SOS Faim, La Paz.

\section{Periódicos}

La Prensa, La Paz 5/06/00, 9/02/02.

\section{Semanarios}

Pulso, La Paz 18-24/01/02, 25-31/01/02, 8-14/02/02, 14-20/ $02 / 03$.

The Economist, Londres 17/08/02; Unit Country Report 08/02. 


\begin{tabular}{|ll|}
\hline & \multicolumn{1}{c|}{ Anexo 1: Siglas } \\
& \\
ADN & Acción Democrática Nacionalista \\
AP & Acuerdo Patriótico \\
APDHB & Asamblea Permanente de Derechos Humanos de Bolivia \\
ASP & Asamblea por la Soberanía de los Pueblos \\
CAO & Cámara Agropecuaria del Oriente \\
CIDOB & Confederación Indígena del Oriente, Chaco y Amazonia de Bolivia \\
COMUNAL & Coordinadora de Movilizaciones Unica Nacional \\
COB & Central Obrera Boliviana \\
CONDEPA & Conciencia de Patria \\
CSUTCB & Confederación Sindical Unica de Trabajadores Campesinos de Bolivia \\
GANPI & Gran Asamblea Nacional de los Pueblos Indígenas \\
IU & Izquierda Unida \\
LyJ & Libertad y Justicia \\
MAS & Movimiento al Socialismo \\
MBL & Movimiento Bolivia Libre \\
MIP & Movimiento Indigenista Pachacuti \\
MIR & Movimiento de Izquierda Revolucionaria \\
MNR & Movimiento Nacionalista Revolucionario \\
MRTKL & Movimiento Revolucionario Tupaj Katari de Liberación \\
MST & Movimiento Sin Tierra \\
NFR & Nueva Fuerza Republicana \\
PS-1 & Partido Socialista-Uno \\
UCS & Unidad Cívica Solidaridad \\
UDP & Unión Democrática y Popular \\
& \\
\hline
\end{tabular}

